\title{
HRM practices that support the employment and social inclusion of workers with an intellectual disability
}

\begin{abstract}
This study examines how HRM practices enhance and/or impede the employment, participation, and wellbeing of workers with intellectual disabilities in three hotels located in Australia. The research employs a case study methodology, including interviews with three HR managers, three department managers, 17 workers with intellectual disabilities, and focus groups of 16 supervisors and 24 work colleagues. We employ social exchange theory and theory on social climate to explore the social inclusion of workers with an intellectual disability. The research found that the opportunities to participate in work are driven primarily by developing a social climate that enables social cohesion through the altruistic motives of managers/supervisors and reciprocal relationships. Our findings lend support for the importance of both formal and informal HR practices, such as inclusive recruitment and selection, mentoring, and training and development, as well as individualised day-to-day support provided by supervisors and colleagues, to improve the participation and wellbeing of workers with an intellectual disability. Our study adds to the limited body of knowledge on the relationship between social exchange and HRM practices, particularly related to workers with disability.
\end{abstract}

\section{Keywords}

Human resource management, Intellectual Disability, Social Exchange Theory (SET), Social Climate, wellbeing 


\section{Introduction}

The purpose of this study is to examine the human resource management (HRM) practices around the experiences of workers with an intellectual disability (WWID) in three leading international hotels operating in Australia. The day-to-day experiences of people with intellectual disabilities and associated HRM practices are under-represented and underresearched in workplace settings (Cavanagh et al., 2016; Foster, 2007). Recent research by Fujimoto, Rentschler, Le Edwards and Hartel (2014) argue that HR policies and practices have not advanced the inclusion of workers with a disability in the workplace. The Australian Institute of Health and Welfare (AIHW) describes intellectual disability as difficulty learning, applying knowledge and making decisions (Madden \& Hogan, 1997). People with intellectual disabilities often have difficulty adjusting to a change in circumstances and may also have difficulty coping in unfamiliar environments. Workers with disabilities experience a disproportionately high level of job insecurity, underemployment and unemployment compared with workers without disabilities (Konrad et al., 2013). The Australian Bureau of Statistics (2013) reports there has been a decline in the employment of people with intellectual disabilities in Australia. In Australia only 39 per cent of WWID were found to be in employment of which 12 per cent were engaged on a full time basis. The unemployment rate of people with intellectual disabilities was reported as 20 per cent, significantly higher than people without a disability at five per cent (Australian Bureau of Statistics, 2013).

Hotels play a major part as both employers and advocates of corporate social responsibility as exemplified by many actively seeking to employ people with disabilities (Groschl, 2007).

Commissioned by the Australia Hotels Association (AHA), a PricewaterhouseCoopers (2009) report found that as one of the most significant industries in the Australian economy, the hotel and accommodation sector provides employment for more than 280,000 people throughout the country. The average Australian hotel employs 34.7 people, with wage expenditure amounting to on average 21.9 per cent of total hotel expenses. Hotels also have a large budget when it comes to training and development, and total industry spending of more than $\$ 70$ million each year (PricewaterhouseCoopers, 2009). The total spending in hotels is estimated to be $\$ 12$ to $\$ 13$ billion each year, generating a significant amount for the Australian economy. In the absence of the hotel sector, household consumption would contract by an estimated $\$ 3.5$ billion, showing just how much the industry is needed within Australia (PricewaterhouseCoopers, 2009). 
In this paper, we draw on Social Exchange Theory [SET] (Blau, 1964; Meeker, 1971) and theories of social climate (Collins \& Smith, 2006) and emphasise a new way of looking at SET by focusing on organisations successful in the employment of WWID and the programs they have in place that ensure a positive social environment. Social climate may be an important factor in strengthening social cohesion of employees through shared cognitions, trust and cooperative networks among employees (Collins \& Smith, 2006). HRM need to provide effective policies and practices that promote inclusion and we suggest this may be facilitated through social climate. However, there needs to be a clear connection between espoused HR policies and practices in action (Kulkarni \& Valk, 2010). Employers also need a more complete understandings of how to effectively support WWID (Houtenville \& Kalargyrou, 2012). Many managers need to be better acquainted with appropriate disability management practices and effective recruitment and retention practices for people with disabilities (Kulkarni \& Valk, 2010). Despite some examples of excellent managerial practice and support of people with disabilities, a number of researchers argue that mainstream HRM does not sufficiently address the complexity surrounding disability or relationships between people with disabilities and organisations (Cook \& Burke-Miller, 2015; Lerner et al., 2004; MacDonald-Wilson, Rogers, Massaro, Lyass, \& Crean, 2002). Participation of workers with intellectual disabilities in the workplace will be affected by the type of HR practices that are employed by the organisation as well as the broader social climate. This study aims to identify the practices that enable the social inclusion and participation of workers with intellectual disabilities. This paper addresses the research question, how do current HRM practices enhance and/or impede the employment, participation, and wellbeing of workers with intellectual disabilities? The scope of the paper is to consider HRM practices and the social inclusion of WWID. The researchers selected three case study sites that a deliberate and purposeful strategy of employing people with intellectual disabilities. This study uses a case study methodology, with three HR managers, three department managers and 17 workers with intellectual disabilities and focus groups with 16 supervisors and 24 work colleagues.

Our contribution will look at intellectual disability from the perspective of multiple actors, including HR managers, department managers, supervisors and work colleagues. The wellbeing of those with an intellectual disability is an important social and political issue as people with disabilities represent one of the largest minority groups in most countries across the world (Lengnick-Hall, 2007). Moreover, we contribute to the dearth of literature on the 
social inclusion/exclusion of people with intellectual disabilities at the workplace (Fevre, Robinson, Lewis, \& Jones, 2013) and unpack the processes through which HRM can enhance the social inclusion of WWID.

The paper is structured in the following way. First, a review of HR literature relative to management and workers with intellectual disabilities is carried out. Second, a review of the key tenets of SET and social climate will be outlined. Third, the methodology of the study will be presented, followed by the results which identify the main factors which influence the management perspectives and the opportunities for people with intellectual disabilities to gain employment. Finally, the implications of this research and avenues for further studies will be discussed.

\section{HR and management practices}

Contemporary research on HRM and disability has primarily focussed on both formal and informal HRM practices (e.g., training and education, mentoring and socialisation processes) and work accommodations of employees with disabilities (Baldridge \& Veiga, 2006; Fujimoto et al., 2014). HR needs to ensure workers with disabilities are placed in sustainable work situations and supported with development programs throughout their employment (Roush, 2009). Sustainable practices should begin with recruitment and ensure the ongoing health and safety of workers with a disability (Bengisu \& Balta, 2011). Bengisu and Balta (2011) argue that organisations should also support inclusion and diversity through corporate social responsibility policies, practices and initiatives that benefit such workers and society as a whole. However, evidence indicates that employers often fail to develop general and HR policies and practices that enable supervisors and colleagues to devote more time and effort in assisting individuals with disability, particularly those with intellectual disabilities (Lysaght, Ouellette-Kuntz, \& Lin, 2012). Many employers will refrain from recruiting workers with disabilities and cite fear, uncertainty and a lack of experience in managing people with intellectual disabilities (Jones \& Schmidt, 2004; Scheid, 2005). Growing research suggests work-orientated inclusion processes largely lead by HRM practitioners have not been particularly effective in developing socially inclusive workplaces (Fujimoto et al., 2014). Workers and job seekers with disabilities often cite employer attitudes and workplace discrimination as barriers to acquiring retaining employment. We argue that HRM and the associated behaviour of managers are critical to enhancing employment rates of workers with 
disabilities (Kaye et al., 2011). In fact, some recent studies suggest that HR management practices that foster social inclusion of workers with disabilities may be positively associated with their wellbeing, worker retention and productivity (Abrams \& Hogg, 2004; Graffam, Shinkfield, Smith, \& Polzin, 2002; Messersmith, Patel, Lepak, \& Gould-Williams, 2011).

The economic participation of individuals with disabilities influences the social policies of many western countries (International Labour Office 2012). In 2006 the United Nations Convention on the Rights of Persons with Disabilities (2006), mandating that every individual with a disability has a right to work on the same basis as their non-disabled peers. Australia is a signatory to the convention and the commitment to the economic participation of people with disabilities is set out in the National Disability Strategy. Approaches have been used in many countries to execute policy aims that include anti-discrimination legislation, quotas for the number of people with disabilities to be employed by large organisations, subsidies to employers to partially cover the wage costs of employing a person with a disability, disability action plans, specialist disability employment services and varied approaches to the provision of employment programs and support (e.g., supported employment, co-worker training). Many innovations are dependent on the knowledge and support of human resource (HR) and other managers throughout organisational hierarchies, hence it is imperative to understand what HRM and management practices are most useful in supporting workers with disabilities. Despite these innovations, discrimination still persists (Fujimoto et al., 2014) and many people with disabilities find it difficult to gain employment (Lerner et al., 2004).

Recruitment is often the first barrier for a worker with a disability (Groschl, 2007; Kaye et al., 2011; Lengnick-Hall, 2007). There appears to be a culture of 'blame' between employers and Government support agencies for not increasing the number of workers with a disability within the work environment. Groschl's (2007) study of 42 hotel HR managers across Canada found that a lack of formalised and systematic HR practices was associated with the lack of recruitment of workers with intellectual disabilities. The apparent lack of HRM practices and policies within the hotel sector taking into account of disability may disadvantage this group of vulnerable workers. Groschl (2007) identified only five of the 42 hotels had a diversity statement, however nothing was specific to employees with disabilities. Employees within organisations that employ human resource (HR) practitioners must be aware of the connection between disability and critical HRM policies and practices (Nafukho, Roessler, \& Kacirek, 2010). Roessler, Hurley and McMahon (2010) argue that human resource professionals could 
implement early identification and discrimination prevention programs to provide reasonable accommodations, and flexible work schedules for people with intellectual disabilities (Roessler, Hurley, \& McMahon, 2010).

Workplace stereotyping of a disability can be seen as one of the main reasons persons with a disability do not gain employment (Shier, Graham, \& Jones, 2009). Evidence suggests that managers often stereotype workers with disabilities particularly intellectual disabilities as those with decreased productivity, poor attendance records and limited ability to perform (Jones \& Schmidt, 2004). The attitudes of managers and colleagues can negatively affect the integration of workers with disabilities into the organisation (Chan et al., 2010). Even when workers with disabilities are in employment, a negative organisational culture may result in their increased job stress and low retention levels (Schur, Kruse, \& Blanck, 2005). Negative employer attitudes are attributed to the often unnecessary turnover of workers with disabilities (Negri, 2009). Stigma, or a negative stereotype has been identified as one of the major reasons why people with mental health disabilities cannot find or retain employment (Krupa, Kirsh, Cockburn, \& Gewurtz, 2009; Scheid, 2005; Schulze \& Angermeyer, 2003; Zissi, Rontos, Papageorgiou, Pierrakou, \& Chtouris, 2007). Conversely, employer support and positive attitudes can influence workers with disabilities to achieve their career goals (Hashim \& Saodah, 2014). Snyder et al. (2010) argue that perceived supervisory support can be associated with an increase in job satisfaction which in effect helps to retain workers with intellectual disabilities.

\section{Intellectual disability and employment}

Recruitment trends suggest that workers with intellectual disabilities are underrepresented within the work force (Australian Bureau of Statistics, 2008; Salkever et al., 2007). However, management recruitment processes and attitudes are evolving to be more inclusive (Gilbride, Stensrud, Ehlers, Evans, \& Peterson, 2000; Gouvier, Sytsma-Jordan, \& Mayville, 2003) towards people with an intellectual disabilities (Luecking, 2011; Morgan \& Alexander, 2005). In 2009, the Australian Bureau of statistics recorded people with an intellectual disability made up 17 per cent of the disability population able to participate in work. For those employed workers with a disability, 49 per cent had a physical disability whereas only 29 per cent had an intellectual disability.

Evidence presented by Gilbride, Stensrud, Ehlers, Evans and Peterson (2000) survey of 200 
employers in the US found that the majority of employers surveyed had employed a worker with an intellectual disability. Moreover, Morgan and Alexander's (2005) research of 534 organisations from service, manufacturing and retail industries in the US illustrated that 30.9 per cent of respondents had previous experience in recruiting individuals with intellectual disabilities. Of these, 97 per cent indicated that the employment of individuals with intellectual disabilities had worked well and that they were willing to recruit individuals with development disabilities in the future. Contrary to the views of many managers, evidence suggests that people with intellectual disabilities that are effectively supported at the workplace are more likely to be highly committed and productive workers (Cavanagh et al., 2016; Fujimoto et al., 2014).

\section{Theoretical Framework}

\section{Social Exchange Theory}

Social exchange relationships are important in explaining the interactions between people (Blau, 1964; Meeker, 1971) and in this case we explore management and supervisors, and workers with an intellectual disability. We argue that Social Exchange Theory (SET) can be useful in explaining the process and outcomes of effective workplace relationships (e.g., employee wellbeing), particularly among people with intellectual disabilities. People with intellectual disabilities often have high levels of organisational commitment and a need to build strong social relationships and to belong at the workplace (Foster, 2007; Luecking, 2011; Tse, 1994). In this study, we examine the factors that impact on workers' with an intellectual disability and use SET to consider social exchange relationships (Cropanzano \& Mitchell, 2005). Social Exchange Theory (SET) is based on reciprocity (Blau, 1964) whereby individuals generally return the benefits they receive, to match the goodwill and helpfulness toward the party with whom they have a social exchange relationship (Cropanzano \& Mitchell, 2005). Gouldner, (1960) argues that reciprocity results from interdependent exchanges, where one party's action is contingent on the other party's behaviour; in folk belief, or the principle that people 'reap the seeds that they sow'; and in social customs which decree how one should act. Research demonstrates that reciprocity enhances work relationships, allowing individuals to be more trusting of and committed to organisations (Molm, Takahashi, \& Peterson, 2000). Meeker (1971) argues that interpersonal exchanges can be treated as individual decisions. There are 6 rules that guide such decisions: reciprocity (the concept of 'giving back' and mutual trust in a relationship); rationality (use of logic to ascertain likely consequences, such as rewards and how to create things that are valued); altruism (seeking benefits for others at a cost to 
ourselves); group gain (benefits are communal and shared as required); status consistency (sharing of benefits and making contributions to the group in order to gain status); and competition (harming others, even at a cost to oneself). In this study, we use Meeker's 6 social exchange rules as a basis to investigate the drivers and processes that influence the management of and the participation of workers with an intellectual disability in the workplace.

\section{Social Climate}

Previous research has highlighted the importance of social inclusion of people with disabilities, especially people with intellectual disabilities (Fevre et al., 2013; Fujimoto et al., 2014). The social impact on a worker with an intellectual disability can be characterised through their social contacts and interactions within a workplace (McNeill, Kreuter, \& Subramanian, 2006). We argue that critical to building the social inclusion of people with intellectual disabilities at the workplace HR managers have to develop HR policies and practices that build a social climate of inclusion. Social climate (SC) is about a 'network of relationships that exists among individuals in some group and to the assets, that are mobilized through the network of social relationships' (Prieto \& Pilar Pérez Santana, 2012, p. 193) incorrect reference. SC centers on the perceptions of a group of people, such as workers, about their shared environment, and in this study it will be the workplace. Collins and Smith (2006, p. 547) define SC as 'the collective set of norms, values, beliefs that express employees' and the interactions that characterize what is really going on in a particular setting. SC is epitomized by trust, cooperation and shared codes and language that exist among individuals within the organisation (Collins \& Smith, 2006; Morris, Snell, \& Wright, 2006; Nahapiet \& Ghoshal, 1998). Consistent with these views we argue that HRM practices (e.g., training and development, mentoring, performance management and recruitment and selection processes) should underpin the development of the social climate within which people with intellectual disabilities work. Recent research has illustrated the additive effects of HRM on building social climates to facilitate knowledge exchange and combination (exchange and combination create new knowledge by connecting previously unconnected ideas and knowledge or recombining previously connected ideas in new ways) (Prieto \& Pilar Pérez Santana, 2012) and the development of intellectual capital (Nahapiet \& Ghoshal, 1998). In this study, through the use of SET and social climate frameworks, we examine three case study hotels to elucidate if HRM practices enhance and/or impede the employment, participation, and wellbeing of workers with intellectual disabilities. 


\section{Method}

We employed a qualitative case study methodology to investigate the participation of workers (Cresswell \& Miller, 2000) and in particular those with an intellectual disability in the workplace. The investigation distinguishes themes of social exchange to provide an in-depth understanding of the drivers and processes that influence the participation of workers in organisational settings (Creswell, 2013). We attended three hotels operating in Australian capital cities and to ensure the anonymity of each we briefly describe the hotels and do not reveal their locations as they may be easily recognised. The three case study sites are leading international hotels with formalised and systematic HR inclusive of training and inclusion policies and procedures for WWID.

Participants included three HR managers; three department managers; 17 workers with intellectual disabilities (identified as such by employers); 16 supervisors and 24 colleagues. Participant workers with an intellectual disability were provided with a research information sheet and they discussed the study with their parents/guardians before voluntarily agreeing to participate in the study. Hannah an example of a question here. Participants ranged in age from 18-55 and worked in different departments at each hotel including, housekeeping; food and beverage, and front office. The majority of workers with disabilities were found back of house $(n=17)$ with only two employed front of house. At hotel 1, one worker with a disability was employed in the restaurant; there were no workers with disabilities found front of house at hotel 2; and at hotel 3 one worker with a disability was employed in the front office department. Institutional ethics approval for the project was granted in 2015.

Throughout the study the participants will be given pseudonyms and further identified as follows: Workers with an Intellectual Disability -WWD; Human Resource Managers - HRM; Department Managers - DM; Supervisors - S; Colleagues - C.

\section{Interviews}

Interviews were carried out with three HR managers, three department managers and 17 workers with intellectual disabilities. The interview guide incorporated trustworthiness questions build around past and present workplace experiences (Denzin, 2003) with WWID. Hannah please include an example here. Interviews generate an increased opportunity for an exchange between the participant and the researcher, where the researcher can develop understandings of participants' beliefs, perceptions and motivations (Hennink, Hutter, \& Bailey, 2011). During the interviews, workers with intellectual disabilities were asked 
questions about how they came to find employment, their level of involvement in work, what benefits they gain from participation, what supports and/or impedes their employment status. HR Managers were asked about each Hotel's policy on disability management, the number of workers with disabilities, how these workers were recruited, whether the hotel receives or knows of any external support available and management support workers with disabilities. Department managers were asked about the organisation of the department, the training of workers with disabilities and their interactions with fellow colleagues.

The HR manager of each of the organisations determined the capacity of an employee with an intellectual disability to consent to the research. Guidelines from the National Statement on Ethical Conduct in Human Research were provided to the HR managers for them to determine the capacity of workers to participate in the study (Lengnick-Hall, 2007). Participants with a disability received a participant information sheet (to be discussed with family two weeks prior to the interviews) and were assured that any personal information about them (e.g. their disability) would not be revealed to any work colleagues during the interview process. The participants were then asked if they had any concerns that may impact on their involvement. Workers with intellectual disabilities were also offered the option to bring a support person (parent/guardian/friend/colleague) into the interview with them.

\section{Focus groups}

Focus groups were conducted with a total of 16 supervisors and 24 work colleagues. Each focus group was carried out by one member of the research team and between five and 10 participants in each focus group, six focus groups were held in total, three for supervisors and three for colleagues. Each focus group was scheduled for approximately forty-five minutes. The focus group method is a form of group interview involving several participants and a facilitator, with a focus on the interaction within the group and joint construction of meaning (Miles \& Huberman, 1994). The purpose of the focus groups was to encourage discussion (Stokes \& Bergin, 2006) amongst supervisors and colleagues regarding the factors that support or inhibit the participation of workers with disabilities in meaningful work. Supervisors were asked about the supervision of workers with disabilities, the inclusion of workers with disabilities into the team, the HR support available and the training they have received to manage a worker with a disability. Colleagues were asked about their working relationship with the workers with a disability. To protect the identity of the participants the actual locations have not been identified and pseudonyms have been used in the reporting of the results. 


\section{Data analysis}

The recordings of the interviews and focus groups were transcribed and analysed using NVivo, following the steps of content analysis outlined by Weber (1985). The first step was to generate a coding framework and a detailed codebook. Initially, an a priori coding framework was established based on the six decision rules of social exchange defined by Meeker (1971), with additional themes being added concomitantly as the analysis progressed. The transcripts of each interview and focus groups were coded independently by two coders until saturation. Two coders were used to ensure the reliability of the coding framework. Where there was disagreement between the coders, a third rater was employed to finalise the coding.

\section{Findings}

Emergent themes were found to support effective HR practices that promote the inclusion of workers with an intellectual disability. Findings were consistent with Meeker's (1971) rules of social exchange and Prieto and Pilar Perez Santana's (2012) conceptualisation of social climate. These two conceptions are merged to give the headings seen in the findings. This has allowed the researchers to increase the depth of the findings. These headings include, altruism and support, rationality and inclusion, group gain and communal benefits and, status consistency, independence and establishing a social climate of inclusion. A further theme underpinning the practices in each of the research sites was the practical HR and management practices used to facilitate the management of workers with intellectual disabilities has been included to complement SET. We found that the managers are mostly responsible for creating a social climate to promote the social inclusion of workers with an intellectual disability. The data reflects the impact on the workers' well-being and their sense of belongingness in the workplace.

\section{HRM Practices}

There were various HRM practices that were identified as being particularly important for workers with intellectual disabilities. In the interviews, these include supervision support, buddy systems, the importance of supervision as demonstrated below:

'The supervisors help me when I need it. They told me how to do my job. They always help me and talk to me'. (Helen, WWD2 - Hotel 1). 
'They [supervisors] helped me learn what I had to so after my training and helped me get used to it. I can talk to them about my job and they tell me how to do things'. (Laura, WWD3 - Hotel 3).

'The supervisors aren't very supportive, they get frustrated with us'. (Stewart, WWD7 - Hotel 2)

'The supervisors are too busy to help, my training was very quick, and they didn't want to be there or help me so I learnt more from the other housekeepers'. (Jack, WWD3 Hotel 2).

'Buddy Systems' are an effective technique to provide ongoing support to workers with disabilities. Often workers may feel more comfortable learning from their peers and this is also a cost-effective way for organisations to ensure that continuous learning, development and support is provided to their works.

'My buddy helped me learn what to do in my new job. I just ask them otherwise it takes me ages to do things'. (Charlotte, WWD3 - Hotel 1)

'My buddy helped me with my rooms and gradually stopped helping me as I learnt how to do it myself; we still use the same technique now. I think it helps our newbies settle in'. (Christie, WWD8 - Hotel 1)

'Every new person gets given one (a buddy) when they start. You get initial training and then your buddy shows you the ropes. You get rostered together so you can ask questions and learn on the job'. (Emma, WWD1 - Hotel 3)

Other HRM factors such as 'support from colleagues' and 'flexible work practices' were also evident in the participants' talk.

'As with all other employees we offer full job support, if anyone feels they are struggling in their role they can speak to their supervisor for help in additional training ....we will offer support.....or will substitute other jobs in their place'. (Alice, DM - Hotel 3)

'I would rather ask for help from the housekeepers, we are like a family and a definite team unit, it's just easier and less hostile than asking the supervisors'. (Tom, WWD 4 - Hotel 2)

'My boss has been really supportive since my diagnosis.....he has helped yet not treated me differently.....there's so much flexibility going to appointments and having time off'. (Bethan, WWD7- Hotel 1)

Support through social relationships was imperative to the participants for them to feel comfortable and confident in their work. The findings highlight that it is important to establish an inclusive work environment for workers with an intellectual disability.

\section{Altruism, reciprocity and building interpersonal relationships}


The managers, department managers, HRM and supervisors all reported altruistic motives for employing and/or working with employees with an intellectual disability. Gouldner, (1960) has suggested that reciprocity is derived from interdependent exchanges such as when one party's action is contingent on the other party's participation such as through training at work. Managers and supervisors discussed the ways in which they include employees with an intellectual disability and for some the ancillary contributions this necessitates:

'All employees receive an induction and full training on their job role.....this may take a bit longer for employees with disabilities.....it can take longer for them to feel comfortable carrying out a job role'. (Alice, DM - Hotel 3)

'We make sure they are integrated and don't point out that they are different then [other] employees do the same'. (David, DM - Hotel 1)

'We offer full support for all our employees, for workers with disabilities this could be additional supervision......we don't make a spectacle of them, they are just normal employees like everyone else doing their job to the best of their ability.....'. (Jane, HRM - Hotel 1).

'...you adapt how you deal with someone [with a disability] depending on who they are. Some people are more responsive to direct requests others you need to coax a bit more'. (Susan, S6 - Hotel 2)

In the three hotels the management ethos of accepting diversity and the integration of people with a difference, has been demonstrated in the above statements. Interestingly, the managers and supervisors were mindful that they needed to provide more assistance and spend more time with WWID for them to survive in their jobs. Their altruistic motivations were found in the ways managers and supervisors wanted to support the workers for mutual gains. Managers and supervisors also reinforced a cycle of reciprocity by helping the workers and earning their trust in the hope they [the workers] will want to contribute and help in the exchange.

\section{Social Climate of Rationality, Inclusion and Equality}

When we explored the social climate of each of the organisations we found the supervisors were mostly involved in the workplace interactions with workers with intellectual disabilities. The responses of the supervisors indicate they are sensitive to ensuring workers are treated equally. The supervisors explained how workers with disabilities are treated differently to other employees and how that may have a negative impact:

'If the employees see management treating them differently then they might think its ok and do the same, which could cause discrimination issues'. (David, DM - Hotel 1). 
'I think it is not fair to single out someone with a disability by managing them differently’. (Michael, S4 - Hotel 1).

'I don't think it would be a good idea to give [WWD] specific training, it is saying that these people are different and we need to treat them differently..... we want everyone to be the same and inclusive'. (Amy, S2 - Hotel 3)

'No one wants to work with them [WWD] really.....some staff shy away from them..... we try to keep them on a job on their own.... which can't be a nice feeling for them'. (James, S1 - Hotel 2)

In these statements the supervisors demonstrate that being rational about what is fair for the workers is about applying logic to each situation. Therefore, their rationality is demonstrated in how they approach the complexities of working with people with a disability, and their attempt at being inclusive whilst working against the resistance of other workers. The supervisors indicate their intrinsic rewards are found in working with people that others [work colleagues] find difficult. Supervisors explained how time-consuming their work is and the level of patience they need when supervising workers with an intellectual disability 'sometimes I explain things slower or repeat so they understand'. (Angie, S1 - Hotel 1)

From the responses of colleagues, it was clear that inclusion tactics are used by supervisors and that these seem to be effective in integrating workers with disabilities into the organisation. Such sensitivity to inclusion is also evident in the talk of colleagues who are aware of their own impact on the inclusion of workers with disabilities.

'Housekeeping tries to treat everyone as normal so we all fit in, there are lots of different people from different backgrounds so it's nice everyone can fit in'. (Elle, C1 - Hotel 1)

'They are just like everyone else there is no difference. We just talk about normal stuff'.(Joshua, C9 - Hotel 2)

'They contribute to the team so why wouldn't they be part of it? The supervisors aren't helpful so we try to bond together as much as we can. They are very helpful, kind and friendly so there is no question of them being part of the team'. (Lee, C3 - Hotel 2)

\section{Group gain and communal benefits}

Individuals generally identify with a work group or team and reciprocate the goodwill and helpfulness toward the party with whom they have a social exchange relationship (Cropanzano \& Mitchell, 2005). We found that the communal benefit of working in a group had positive outcomes for workers with intellectual disabilities was mostly identified as a sense of belonging. Many of the participants supported the notion of belonging and made statements such as: 
'I like feeling secure. My last job was casual so it's nice to be permanent. I still get worried and I'm shy but I've got a lot better because of this job. I like being in a big team. There are lots of people so it's nice to feel wanted. I feel like I belong here. It's good, I feel happy'. (Anthony, WWD4 - Hotel 1)

'Working makes me feel happy and like I am needed' (Bryony, WWD9 - Hotel 1).

'I like being part of a team and knowing I have helped to do things'. (Jack, WWD3 Hotel 2)

'....everyone here is like family now. It's fun to come to work and see everyone'. (Sean, WWD4 - Hotel 2)

'I didn't have one [job] but now I do I can tell them [my brothers] about mine. It makes me feel more part of my family..... like my job, I like fitting in with my friends and at home with my brothers'. (Stewart, WWD7 - Hotel 2)

'I just enjoy having a job I like and fitting in'. (Karen, WWD6 - Hotel 3)

Showing that gains are not only sought for workers with disabilities, colleagues from all three hotels indicated that they have benefited from working with people with disabilities.

'I was nervous (working with a WWD) at the start because I hadn't been around people with downs syndrome before but you get used to it and you see they are just like you really'. (Jenn, C2 - Hotel 2)

'We are lucky that everyone including our workers with disabilities are supportive here, it's an enjoyable place to work'. (Christopher, C2 - hotel 3)

'Our F\&B attendant is a bit of a celebrity, he's like the godfather - he's always in the middle of things’. (Oscar, C5 - Hotel 1)

Group gain for colleagues was found in valuing their own contributions towards helping WWID in their daily work. For the participants the gain was about WWID having money and being independent. Being self-sufficient correlates with the need of WWD's to be 'normal' and fitting with an organisation.

\section{Status consistency and independence}

In the interviews the majority of the participants expressed how the opportunity to work provided them with a sense of independence and a direction in their lives beyond the security of their family homes. Charlotte, (WWD3 from Hotel 1) summed up the sentiments that were very similar across all of the participants:

'I like having a job.....I get to do that more here than at home. It gives me freedom because I make my way here and home on the bus. I am more confident and mum says I am happier and don't argue with her as much anymore. I like what I do and who I work with.....making money and being happy'. 
Other participants referred to directly to independence and a sense of self-sufficiency and made statements such as:

'I feel independent because I can spend money I make on what I want and not what my parents say’. (Paul, WWD5 - Hotel 2)

'Just like anyone it is great to have money coming in and be independent.... I can do everything everyone else does’. (Emma, WWD1 - Hotel 3)

'I enjoy being independent and making my own money'. (Chelsea, WWD6 - Hotel 2)

'It's great, having money helps [laughs]. I have always tried to be self-sufficient'. (Anthony, WWD4 - Hotel 1)

A sense of purpose and feeling 'normal' was found in much of the participants' talk in each of the focus group sessions:

'It is ok.....getting up and doing something and I can do my job'. (Peter, WWD1 - Hotel 1)

'I like working because I am doing things and not just at home'. (Sarah, WWD4 - Hotel 3)

I like having a job. I like having something to do every day and knowing what I am going to do'. (Paul, WWD5 - Hotel 2)

'It is the best feeling.....I am responsible for getting the bus, getting my uniform and making guests enjoy their stay. I know I have a disability, but in my head I am just like everyone else....this job makes me feel more normal'. (Olivia, WWD2 - Hotel 3)

The maximum value was found in the exchange about how WWID feel 'responsible' for everyday activities such as catching the bus to work. Hence, status consistency was evident in workers desire for independence and the fact that their work gave them a sense of purpose and helped them feel 'normal'.

\section{Discussion and Conclusion}

This study set out to examine, in three hotels that actively employed people with an intellectual disability, whether HRM practices enhanced and/or impeded the employment, participation, and wellbeing of these workers. We reported that workers with intellectual disabilities positively responded to a social climate of inclusion where they felt like 'everybody else and part of the team' coupled with individualised day-to-day support from their immediate manager and work colleagues. Results demonstrated that HRM played an important role in facilitating a social climate of inclusion and enabling the participation of people with an intellectual 
disability at the workplace (from their perspective). Our results raise some important implications for HRM theory and practice. We discussion these in turn.

First, mainstream HRM is underpinned by a competitive model and is almost silent on the challenges associated with workers with disabilities. In fact, mainstream HRM textbooks only give cursory attention to the management of people with disabilities even though according to a United Nations Report globally almost one in ten people have a disability (Kulkarni \& Valk, 2010; United Nations, 2009). HRM is a set of techniques that influence the way work is carried out, but often fails to understand 'difference' and how to effectively manage difference purposefully to build competitive advantage (Foster, 2007). This is an important issue because despite equal employment and anti-discrimination legislation there is substantial evidence that HRM practices and manager behaviour often disadvantage people with disabilities (Fevre et al., 2013; Fujimoto et al., 2014). The results of our study show a different picture in which through a process of HRM practices and supportive management, a social climate of inclusion enabled workers with disabilities to feel wanted and full members of the organisational community. We suggest HRM needs to recalibrate to be more inclusive of 'difference'. HR practitioners need to raise their heads above managerial rhetoric and develop a credible balance between competitive approaches and their social responsibilities. We argue that organisations have a responsibility to the community within which they operate and they need to develop approaches that embrace diversity. Evidence suggests diverse organisations are more successful through 'leveraging marketplace opportunities, greater creativity, higher quality team issue solving for obtaining competitive advantage'(Fujimoto et al., 2014, p. 519).

Second, our results demonstrate the efficacy of the appropriate implementation of human resource management practices in the context of the employment of people with intellectual disability (Nafukho et al., 2010). The role of line managers is crucial not only to build a social climate of inclusion but also provide day-to-day support of workers with an intellectual disability (Foster, 2007; Kulkarni \& Valk, 2010). Formalised HRM practices that meet statutory minima are important but need to be coupled with purposeful and effective day-today management. Ongoing support from the direct supervisor and additional supervision when needed is also particularly important, as this helps the workers to learn how to do their job. It is important that extra supervision and support be provided 'as needed', which may require supervisions to have continuous and close contact with workers to ensure that additional support is provided. In line with Foster (2007) we argue that workplace adjustments must be 
tailored to individual circumstances and must be managed flexibly which necessitates that 'managers understanding the concept of 'difference' and how 'different treatment contrasts with the 'equal treatment' approach of EO legislation' (p. 69) based on the concept that all people are equal regarding their rights. Colleagues played an important role supporting workers with intellectual disabilities. Colleagues also clearly demonstrated that group gain and communal benefits were not only essential for workers with disabilities, but colleagues themselves benefiting from working with people with disabilities. Due to an increased exposure to WWD's, colleagues' acceptance of people with disabilities within the community can also increase (Kontosh, Fletcher, Frain, \& Winland-Brown, 2007). Although, it will be interesting if organisations reach a point where the acceptance of difference at work reaches a level where no one has to 'push' inclusion.

Third, through being part of an inclusive social climate our study provides some evidence that workers with intellectual disabilities can feel empowered and have a heightened sense of commitment to the organisation (Brown, 2000; Van Der Vegt \& Bunderson, 2005). It is this perceived social fairness connected to the social climate that can support the empowerment of workers with disabilities (Graffam et al., 2002). Our study lends some support to Lawler's (1992) argument that HR practices, such as training and team work can initiate trust and empower worker's through feelings of inclusion. By improving the social climate of the organisation through HR practices, workers with disabilities can perceive enhanced wellbeing and some willingness for high performance (Jiang \& Liu, 2015).

Fourth, the themes emerging from this study closely align with the exchange decision rules posited by Meeker (1971) and social climate (Collins \& Smith, 2006; Morris et al., 2006; Nahapiet \& Ghoshal, 1998). The themes include altruism and reciprocity, rationality and inclusion, group gain and communal benefits and status consistency and independence which encourage individuals to participate in social exchanges in the workplace. These social exchanges facilitate trust between organisational participants, cooperation and a common organisational language which are the fundamental tenets of social climate. It is clear that HRM functions including training and education for all organisational participants particularly managers and strong leadership and messaging from the top are crucial in establishing a social climate of inclusion which in turn may impact the wellbeing of people with disability. 
Most of the workers corresponded to Meeker's (1971) exchange rules mainly through group gain and communal benefits, rationality and inclusion and status consistency and independence. Workers mainly demonstrated group gain and communal benefits in their sense of belonging and their enjoyment the fact that they were part of something and fitted in to a team and an organisation. Workers likening their team involvement in the organisation to feeling like a family. Status consistency and independence was also evident when workers talked about how they enjoyed being independent. The fact that they were able to set goals gave them not only a sense of achievement, but also a sense of normality. Rationality and inclusion was apparent through workers pleasure to receive monetary awards for their effort and performance which enabled their independence and their ability to support themselves financially.

For managers and supervisors Meeker's (1971) exchange rules of altruism and reciprocity and rationality and inclusion were particularly distinct. Some managers exhibited elements of altruism in regards to their views on workers with disabilities. While there was clear awareness of the importance of inclusive behaviour and strategies were commonly used to enable this type of behaviour. For example, they 'don't point out that they are different' and 'don't make a spectacle of them', 'make sure they are integrated' and 'like everyone else'. Reciprocity was evident with managers ensuring workers were treated equal and not wanting to make anyone feel isolated or excluded. Managers were aware of the importance of taking an inclusive approach and were conscious that singling workers with disabilities out through offering additional or specialised training may alienate them and reduce their sense of efficacy on the job. Rationality and inclusion was identified as management became aware of the importance of having inclusive practices and that a failure to have such practices could lead to potential discrimination cases.

\section{Contribution to SET theory}

The research has shown a link between SET and social climate. Through using Meeker's (1971) exchange rules organisations can create a positive social climate not only for WWID's but for all employees. For example, group gain in the form of team work can initiate trust and empowerment through feelings of inclusion (Lawler, 1992). The use of social exchange to enhance social climate seems to improve workers wellbeing and their willingness to perform (Jiang \& Liu, 2015). SET can further be linked to the wellbeing of WWID's through inclusive HR practices underpinned by Meeker's (1971) SET rules (e.g. reciprocity linked to 
management and colleague support, rationality related to rewards and group gain through teamwork) (Abrams \& Hogg, 2004; Messersmith et al., 2011). Meeker’s (1971) six rules can be used as a basis to highlight areas of focus for the management of WWID's. For example, management practice could focus on group gain through the use of teamwork and ensuring WWID's have a clearly constructed team to work with. As the research has illustrated, WWID's enjoy that they were part of something and fitted in to a team environment.

\section{Managerial implications}

From a formal management perspective, and to fully embed WWID in the organisation, managers will need to ensure HR policies and practices work towards full participation for all workers. There is a clear discrepancy between what organisations say they do and what they do in practice in regards to disability practices in the workplace and this could provide to be problematic for organisations if this is not addressed. The data provided evidence of WWID feeling empowered and more committed to an organisation when line managers promoted an inclusive social climate. However, we cannot predict how individual managers and/or supervisors will manage individual WWID but we can suggest any new organisations consider all the variables in social exchange and attempt to adopt them in their organisations for the overall benefit of WWID. Our results also raise implications for the way in which managers are trained in Australian business schools with greater attention needed to be placed on understanding and effectively managing diversity to bring about change in managerial and organisational attitudes. Hence, from an informal perspective the paper contributes to practical understandings of the workplace experiences of WWID. The experiences highlighted in this paper, such as enhanced trust through social exchanges, may well enhance the way managers apply a more personal approach to future orientation and the ongoing support for these workers. For instance, management could take the positive experiences of WWID who have been involved in the orientation 'buddy system' and apply the same approach to other similar programs for continuing training and development of WWID.

\section{Limitations}

The research problem was investigated at three hotel sites which limits the interpretation of findings to participants within the three sites. A larger study may reveal more indicators of social climate that does not lead to positive outcomes. As this research focuses on the hospitality industry and hotels, limitations also arise when generalising the findings to other 
employment industries. Future research should focus on a range of industries. This research is also limited by the focus on workers with intellectual disabilities. Due to the limited research focus on intellectual disabilities, this can also be seen as a strength of the research, however, it is difficult to apply the findings to other disability types. Also, after interpreting the findings we found that the scope of our study could have been extended by analysing HR policies and procedures prior to the study and by including participant observations during data collection.

\section{Future research}

Due to the limited research on SET and workers with intellectual disabilities, this paper is as the forefront of research in this area. As the research findings indicate a link between SET and the management of WWID's, further research could explore these links identifying which out of Meekers' six rules relate best to and are influential on the performance of WWID. There is a lack of research regarding the links between SET and social climate, therefore, additional future research could be explored on, not only WWID's but other disabilities and the general employee work population. We call for further research on HRM and intellectual disability that continues to unpack HRM systems of best practice organisations to find evidence of how HRM practices can further enable the full participation and enhance the wellbeing of people with intellectual disabilities.

In conclusion, our findings lend support for the importance of formal and informal HR practices, as well as individualised day-to-day support provided by supervisors and colleagues, to improve the participation and wellbeing of workers with an intellectual disability. We reported on the social processes, namely social climate and social exchange through which HRM seemed to impact the wellbeing of people with intellectual disabilities. Despite some evidence of the inability of HRM to have a positive effect on the employment and support of people with disabilities it is clear, at least in our the case studies, that certain configurations of HRM as mentioned above have the potential to positively affect the wellbeing of workers with intellectual disabilities. 


\section{References}

Abrams, D., \& Hogg, M. A. (2004). Collective identity: Group membership and self-conception. Self and social identity, 147-181.

Australian Bureau of Statistics. (2008). Accomodation Services Australia. (8695.0). Canberra: Australian Bureau of Statisticcs.

Australian Bureau of Statistics. (2013). Disability, Ageing and Carers. (4430.0). Canberra: Australian Bureau of Statistics.

Baldridge, D. C., \& Veiga, J. F. (2006). The impact of anticipated social consequences on recurring disability accommodation requests. Journal of Management, 32(1), 158-179.

Barnes, C., \& Mercer, G. (1997). Breaking the mould? An introduction to doing disability research. Doing disability research, 1, 1-14.

Blau, P. M. (1964). Exchange and power in social life: Transaction Publishers.

Brown, R. (2000). Social identity theory: Past achievements, current problems and future challenges. European Journal of Social Psychology, 30(6), 745-778.

Cavanagh, J., Meacham, H., Bartram, T., Oakman, J., Bigby, C., \& Fossey, E. (2016). Supporting workers with disabilities: A scoping review of the role of human resource management in contemporary organisations. Asia Pacific Journal of Human Resources.

Chan, F., Strauser, D., Maher, P., Lee, E., Jones, R., \& Johnson, E. T. (2010). Demand-side factors related to employment of people with disabilities: A survey of employers in the midwest region of the United States. Journal of Occupational Rehabilitation, 20(4), 412-419. doi:10.1007/s10926-010-9252-6

Collins, C. J., \& Smith, K. (2006). Knowledge exchange and combination: The role of human resource practices in the performance of high-tech firms. Academy of management Journal, 49, 544560.

Cook, J. A., \& Burke-Miller, J. K. (2015). Reasons for job separations in a cohort of workers with psychiatric disabilities. Journal of Rehabilitation Research \& Development, 52(4), 371-384.

Cropanzano, R., \& Mitchell, M. S. (2005). Social exchange theory: An interdisciplinary review. Journal of Management, 31(6), 874-900.

Fevre, R., Robinson, A., Lewis, D., \& Jones, T. (2013). The ill-treatment of employees with disabilities in British workplaces. Work, Employment \& Society, 27(2), 288-307.

Foster, D. (2007). Legal obligation or personal lottery? Employee experiences of disability and the negotiation of adjustments in the public sector workplace. Work, Employment \& Society, 21(1), 67-84.

Fujimoto, Y., Rentschler, R., Le, H., Edwards, D., \& Härtel, C. E. (2014). Lessons learned from community organizations: Inclusion of people with disabilities and others. British Journal of Management, 25(3), 518-537.

Gilbride, D., Stensrud, R., Ehlers, C., Evans, E., \& Peterson, C. (2000). Employers' attitudes toward hiring persons with disabilities and vocational rehabilitation services. Journal of Rehabilitation, 66(4), 17.

Gouldner, A. W. (1960). The norm of reciprocity: A preliminary statement. American Sociological Review, 161-178.

Gouvier, W. D., Sytsma-Jordan, \& Mayville, S. (2003). Patterns of discrimination in hiring job applicants with disabilities: The role of disability type, job complexity, and public contact. Rehabilitation Psychology, 48(3), 175-181.

Graffam, J., Shinkfield, A., Smith, K., \& Polzin, U. (2002). Factors that influence employer decisions in hiring and retaining an employee with a disability. Journal of Vocational Rehabilitation, 17(3), 175-181.

Groschl, S. (2007). An exploration of HR policies and practices affecting the integration of persons with disabilities in the hotel industry in major Canadian tourism destinations. International Journal of Hospitality Management, 26(3), 666-686. 
Hashim, J., \& Saodah, W. (2014). Predictors to employees with disabilities' organisational behaviour and involvement in employment. Equality, Diversity and Inclusion: An International Journal, 33(2), 193-209.

Hennink, M., Hutter, I., \& Bailey, A. (2011). Qualitative research methods: Los Angeles: Sage Publications Ltd.

Houtenville, A., \& Kalargyrou, V. (2012). People with disabilities: Employers' perspectives on recruitment practices, strategies, and challenges in leisure and hospitality. Cornell Hospitality Quarterly, 53(1), 40-52.

Jiang, J. Y., \& Liu, C.-W. (2015). High performance work systems and organizational effectiveness: The mediating role of social capital. Human Resource Management Review, 25(1), 126-137.

Jones, P., \& Schmidt, R. A. (2004). Retail employment and disability. International Journal of Retail \& Distribution Management, 32(8), 426-429. doi:10.1108/09590550410549293

Kaye, H., Jans, H., \& Jones, E. (2011). Why don't employers Hire and retain workers with disabilities? Journal of Occupational Rehabilitation, 21(4), 526-536.

Konrad, A. M., Moore, M. E., Ng, E. S. W., Doherty, A. J., \& Breward, K. (2013). Temporary Work, Underemployment and Workplace Accommodations: Relationship to Well-being for Workers with Disabilities. British Journal of Management, 24, 367-382.

Kontosh, L. G., Fletcher, I., Frain, M., \& Winland-Brown, J. (2007). Work place issues surrounding healthcare professionals with disabilities in the current labor market. Work: Journal of Prevention, Assessment \& Rehabilitation, 29(4), 295-302.

Krupa, T., Kirsh, B., Cockburn, L., \& Gewurtz. (2009). Understanding the stigma of mental illness in employment. Work, 33, 413-425.

Kulkarni, M., \& Valk, R. (2010). Don't ask, don't tell: Two views on human resource practices for people with disabilities. IIMG Management Review, 22(1), 137-146.

Lawler, E. E. (1992). The ultimate advantage: Creating the high-involvement organization: JosseyBass Inc Pub.

Lengnick-Hall, M. L. (2007). Hidden talent: How leading companies hire, retain, and benefit from people with disabilities: Greenwood Publishing Group.

Lerner, D., Adler, D. A., Chang, H., Lapitsky, L., Hood, M. Y., Perissinotto, C., . . Rogers, W. H. (2004). Unemployment, job retention, and productivity loss among employees with depression. Psychiatric Services, 55(12), 1371-1378.

Luecking, R. G. (2011). Connecting employers with people who have intellectual disability. Intellectual and developmental disabilities, 49(4), 261-273.

Lysaght, R., Ouellette-Kuntz, H., \& Lin, C.-J. (2012). Untapped potential: Perspectives on the employment of people with intellectual disability. Work: A Journal of Prevention, Assessment and Rehabilitation, 41, 409-422.

MacDonald-Wilson, K. L., Rogers, E. S., Massaro, J. M., Lyass, A., \& Crean, T. (2002). An investigation of reasonable workplace accommodations for people with psychiatric disabilities: Quantitative findings from a multi-site study. Community Mental Health Journal, 38, 35-50.

Madden, R., \& Hogan, T. (1997). The definition of disability in Australia: moving towards national consistency. . Retrieved from Canberra:

McConkey, R. (2007). Variations in the social inclusion of people with intellectual disabilities in supported living schemes and residential settings. Journal of Intellectual Disability Research, 51(3), 207-217.

McNeill, L. H., Kreuter, M. W., \& Subramanian, S. V. (2006). Social environment and physical activity: A review of concepts and evidence. Social Science and Medicine, 63(4), 1011-1022.

Meeker, B. F. (1971). Decisions and exchange. American Sociological Review, 485-495.

Messersmith, J. G., Patel, P. C., Lepak, D. P., \& Gould-Williams, J. S. (2011). Unlocking the black box: exploring the link between high-performance work systems and performance. Journal of Applied Psychology, 96(6), 1105.

Miles, M. B., \& Huberman, A. M. (1994). Qualitative data analysis: An expanded sourcebook: Sage. 
Molm, L. D., Takahashi, N., \& Peterson, G. (2000). Risk and trust in social exchange: An experimental test of a classical proposition. American Journal of Sociology, 1396-1427.

Morgan, R. L., \& Alexander, M. (2005). The employer's perception: Employment of individuals with developmental disabilities. Journal of Vocational Rehabilitation, 23(1), 39-49.

Morris, S. S., Snell, S. A., \& Wright, P. M. (2006). A resource-based view of international human resources: Toward a framework of integrative and creative capabilities. Handbook of research in international human resource management, 433-448.

Nafukho, F. M., Roessler, R. T., \& Kacirek, K. (2010). Disability as a diversity factor: Implications for human resource practices. Advances in Developing Human Resources, 12(4), 395.

Nahapiet, J., \& Ghoshal, S. (1998). Social capital, intellectual capital, and the organizational advantage. Academy of management review, 23(2), 242-266.

Negri, L. (2009). Why has a woman with mental illness been fired? Discourses on fairness and diversity management. Work, 33(1), 35-42. doi:10.3233/WOR-2009-0841

Prieto, I. M., \& Pilar Pérez Santana, M. (2012). Building ambidexterity: The role of human resource practices in the performance of firms from Spain. Human Resource Management, 51(2), 189211.

Roessler, R. T., Hurley, J. E., \& McMahon, B. T. (2010). A comparison of allegations and resolutions involving issues of discharge versus constructive discharge: Implications for diversity management. Advances in Developing Human Resources, 12(4), 407-428.

Salkever, D. S., Karakus, M. C., Slade, E. P., Harding, C. M., Hough, R. L., Rosenheck, R. A., . . Yamada, A. M. (2007). Measures and predictors of community-based employment and earnings of persons with schizophrenia in a multisite study. Psychiatric Services, 58(3), 315324.

Scheid, T. L. (2005). Stigma as a barrier to employment: Mental disability and the Americans with Disabilities Act. International Journal of Law and Psychiatry, 28(6), 670-690.

Schulze, B., \& Angermeyer, C. (2003). Subjective experiences of stigma. A focus group study of schizophrenic patients, their relatives and mental health professionals. Social Science \& Medicine, 56, 299-312.

Schur, L., Kruse, D., \& Blanck, P. (2005). Corporate culture and the employment of persons with disabilities. Behavioral Sciences \& the Law, 23(1), 3-20.

Schur, L., Kruse, D., Blasi, J., \& Blanck, P. (2009). Is disability disabling in all workplaces? Workplace disparities and corporate culture. Industrial Relations, 48(3), 381-410.

Shah, H., \& Marks, N. (2004). A well-being manifesto for a flourishing society. London: The New Economics Foundation.

Shier, M., Graham, J. R., \& Jones, M. E. (2009). Barriers to employment as experienced by disabled people: A qualitative analysis in Calgary and Regina, Canada. Disability \& Society, 24(1), 6375.

Snyder, L., Carmichael, J., Blackwell, L., Cleveland, J., \& Thornton, G. (2010). Perceptions of discrimination and justice among employees with disabilities. Employee Responsibilities \& Rights Journal, 22(1), 5-19. doi:10.1007/s10672-009-9107-5

Tse, J. (1994). Employers' expectations and evaluation of the job performance of employees with intellectual disability. Australia and New Zealand Journal of Developmental Disabilities, 19(2), 139-147.

United Nations. (2009). Mainstreaming Disability in MDG Policies, Processes and Mechanisms: Development for All (16.34). Retrieved from Geneva:

Van Der Vegt, G. S., \& Bunderson, J. S. (2005). Learning and performance in multidisciplinary teams: The importance of collective team identification. Academy of management Journal, 48(3), 532-547.

Weber, M. (1985). A method for multi-attribute decision-making with incomplete information. Management Science, 31, B65-B71. 
Zissi, A., Rontos, C., Papageorgiou, D., Pierrakou, C., \& Chtouris, S. (2007). Greek employers' attitudes to employing people with disabilities: Effects of the type of disability. Scandinavian Journal of Disability Research, 9, 14-25.

Denzin, N. K. (2003). Performance ethnography: Critical pedagogy and the politics of culture. Thousand Oaks, CA: Sage Publications.

Creswell, J.W. 2013 Research design: Qualitative, quantitative, and mixed methods approaches. Thousand Oaks, CA: Sage Publications.

Cresswell, J.W. and Miller, D.L. Determining validity in qualitative inquiry. Theory into Practice 39 (3) 124-130.

Stokes, D. and Bergin, R. (2006) "Methodology or “methodolatry”? An evaluation of focus groups and depth interviews", Qualitative Market Research: An International Journal, Vol. 9 Iss: 1 , pp.26 - 37.

Bengisu, M., \& Balta, S. 2011. Employment of the workforce with disabilities in the hospitality industry. Journal of Sustainable Tourism, 19(1): 35-57.

Roush, S. 2009. The Menu Approach to supported employment for individuals with severe and persistent mental illness: Outcomes in an Oregon community based program. Work, 34(1): 45-51. 